\title{
Synthesis of $\gamma-\mathrm{Al}_{2} \mathrm{O}_{3}$ Catalyst Support from Kaolin of Indonesian Origin
}

\author{
Tjokorde Walmiki Samadhi, Subagjo, Kevin R. Lismana \& Khasin Fuadi \\ Chemical Engineering Program \\ Faculty of Industrial Technology, Bandung Institute of Technology \\ Bandung, Indonesia \\ Email: twsamadhi@che.itb.ac.id
}

\begin{abstract}
Kaolin has been identified as a potential raw material for the production of $\gamma-\mathrm{Al}_{2} \mathrm{O}_{3}$ for hydrotreating catalyst support. This work explores the technical feasibility of applying the potassium hydroxide $(\mathrm{KOH})$ extraction synthesis route on kaolin from the Belitung Island in Indonesia. The application of a published synthesis method to Belitung kaolin requires an approximately twofold increase in kaolin calcination time, an increase in kaolin calcination temperature from 950 to $1000^{\circ} \mathrm{C}$, and a tenfold increase in metakaolin extraction time, to obtain a specific surface area higher than $200 \mathrm{~m}^{2} / \mathrm{g}$. The highest specific surface area of $233 \mathrm{~m}^{2} / \mathrm{g}$ was obtained when the kaolin was calcined at $1000^{\circ} \mathrm{C}$ for 24 hours, and the metakaolin was extracted by concentrated $\mathrm{KOH}$ solution for 12 hours. Phase characterization of the final product confirmed the formation of $\gamma-\mathrm{Al}_{2} \mathrm{O}_{3}$, but with the inclusion of low-surface area $\alpha-\mathrm{Al}_{2} \mathrm{O}_{3}$ phase.
\end{abstract}

Keywords: acid leaching; $\gamma$-alumina; catalyst support; hydrotreating; kaolin.

\section{$1 \quad$ Introduction}

The global petroleum-based energy market has recently been marked by several opposing trends. Market demand has been characterized with a generally increasing demand volume for various petroleum fuels, and regulatory shift towards cleaner-burning fuels with lower sulfur and heavy metals content. The latter trend is primarily due to the need to reduce emission levels generated by combustion engines and to increase the thermal efficiency of the engines. On the other hand, fuel production has been characterized by a shift in the global crude oil supply towards heavier, more difficult-to-refine crudes with increasing concentrations of impurities such as sulfur, metals, oxygen, and nitrogen compounds.

These opposing trends have increased the prominence of refinery process technologies that rely on hydrogen to convert crude oil fractions into valuable fuels and other derivative products. To date, the so-called hydroprocessing is still regarded as the most effective process technology when dealing with high impurity, heavy to extremely heavy crude oils. Hydroprocessing encompasses a 
wide range of process objectives, including cracking (hydrocracking), removal of impurities (for example the hydrodesulfurization, hydrodemetallization, hydrodeoxygenation processes), and improvement of fuel physical properties (generally known as hydrotreating process).

Among the wide range of hydroprocessing technologies, hydrotreating ranks as among the most widely employed. Global capacity data of catalytic processing units in petroleum refineries collected by Silvy [1] indicate that hydrotreating boasts the highest global capacity and fastest growth compared to other major catalytic processes such as fluid catalytic cracking, hydrocracking, reforming, and isomerization (see Figure 1).

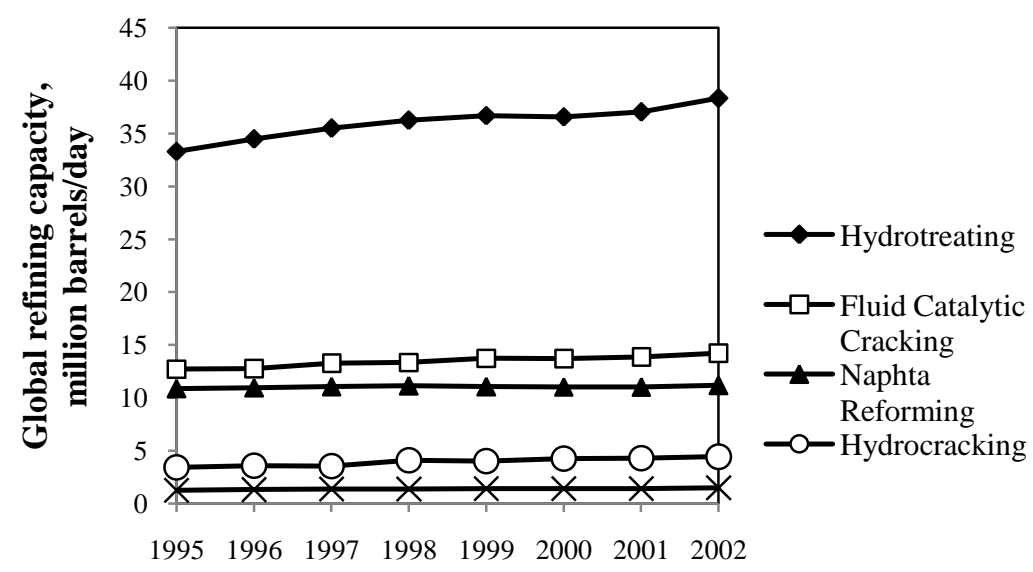

Year

Figure 1 Global capacity trend of major catalytic units in petroleum refineries in 1995-2002 [1].

This global increase in hydroprocessing capacity is naturally accompanied by an increase in the demand of solid catalysts required by these processes. As an indicative trend, the Shell multinational oil company has forecasted that the global demand for hydrotreating catalysts is likely to increase at an annual growth rate of $3-5 \%$ in the foreseeable future [2].

The objective of this experimental research is to evaluate the technical feasibility of the utilization of Indonesian kaolin as a raw material for the manufacture of hydrotreating catalyst support. This process is regarded as having a strategic importance in the national fuel supply security, since it is responsible for the improvement of physical properties of petroleum fuels 
through the reduction of sulfur and metals, and through the reduction of polymerization susceptibility of the fuels.

This research shall involve the utilization of kaolin as a precursor for the synthesis of $\gamma-\mathrm{Al}_{2} \mathrm{O}_{3}$, one of the most widely used catalyst support material for hydrotreating. While the selected synthesis route is not a novel technology, properties of naturally-occurring minerals are highly dependent on their origin and mineralogy. This implies that even a highly detailed synthesis method that has been established for a specific mineral has to be verified (and often needs to be adjusted) when the source of mineral is altered. Therefore, proving that available synthesis methods are applicable to Indonesian minerals is of utmost practical significance.

As a preliminary developmental study, the technical feasibility of $\gamma-\mathrm{Al}_{2} \mathrm{O}_{3}$ is synthesized from Indonesian kaolin in this work is judged by the key physical properties that characterize its role as a catalyst support, namely its specific surface area, pore volume, and crystalline phase distribution. If the physical properties of the Indonesian kaolin-derived $\gamma-\mathrm{Al}_{2} \mathrm{O}_{3}$ are deemed competitive, then this study may form a basis for the development of a high added-value alternative processing route for the Indonesian mineral industry.

The low cost of kaolin and the existence of large, good quality kaolin reserves in the Bangka Belitung, South Kalimantan, and West Kalimantan provinces as listed in Table 1, suggest the prospect for long-term production of $\gamma-\mathrm{Al}_{2} \mathrm{O}_{3}$ to bolster the domestic fuel refining industry.

Table 1 Major kaolin reserves in Indonesia [3-5].

\begin{tabular}{cc}
\hline Province & Estimated reserve, tons \\
\hline Bangka Belitung & $224,300,000$ \\
South Kalimantan & $194,187,800$ \\
West Kalimantan & $317,000,000$ \\
\hline
\end{tabular}

\section{$2 \quad$ Literature Review}

Commercial hydroprocessing catalysts are typically $\mathrm{Ni} /$ Co-promoted $\mathrm{Ni} / \mathrm{W}$ sulfide supported by $\gamma-\mathrm{Al}_{2} \mathrm{O}_{3}$ or silica-alumina $\left(\mathrm{SiO}_{2}-\mathrm{Al}_{2} \mathrm{O}_{3}\right)$. The main purpose of catalyst support is to disperse the active catalytic metal particles and to absorb heat during operation. The nanometer-sized active metal particles are susceptible to sintering (agglomeration of particles due to partial fusion at high temperatures). Thus, the presence of the catalyst support with its large specific surface area serves to protect the active metal particles from sintering which reduces the activity of the catalyst [6]. 
As a catalyst support, $\gamma-\mathrm{Al}_{2} \mathrm{O}_{3}$ offers several advantages. This material provides a large specific surface area of $50-300 \mathrm{~m}^{2} / \mathrm{g}$, mesopore size in the $5-15 \mathrm{~nm}$ range, a pore volume of approximately $0.6 \mathrm{~cm}^{3} / \mathrm{g}$, a high thermal stability, and the ability to be formed into various geometries for fixed bed reactors by extrusion or pelletizing. As catalyst support for fixed bed reactors, $\gamma-\mathrm{Al}_{2} \mathrm{O}_{3}$ provides good mechanical integrity [6].

Large-scale production of $\gamma-\mathrm{Al}_{2} \mathrm{O}_{3}$ generally utilizes boehmite $(\mathrm{AlOOH})$ or gibbsite $\left(\mathrm{Al}(\mathrm{OH})_{3}\right)$ as precursors. Under heating, these hydrated aluminas undergo removal of crystalline water, followed by a series of polymorphic transitions as described in Figure 2. Boehmite and gibbsite are themselves intermediate materials in the production of metallic aluminum from raw minerals such as bauxite.

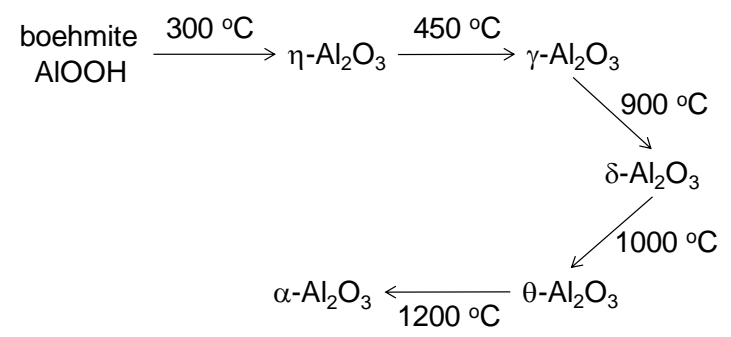

Figure 2 Boehmite dehydration and polymorphic phase transition route in the $\mathrm{Al}_{2} \mathrm{O}_{3}$ system [7].

In his study on soil chemistry, Huang [8] described the formation of boehmite from kaolinite and water under hydrothermal conditions through the following reaction:

$$
\mathrm{Al}_{2} \mathrm{Si}_{2} \mathrm{O}_{5}(\mathrm{OH})_{4}+3 \mathrm{H}_{2} \mathrm{O} \rightarrow 2 \mathrm{AlOOH}+2 \mathrm{H}_{4} \mathrm{SiO}_{4}(a q)
$$

The reaction was undertaken in dilute $\mathrm{KCl}$ solution at temperatures between $200-275^{\circ} \mathrm{C}$ and a pressure of $500 \mathrm{bar}$. The X-ray diffraction pattern of the solid reaction product resembled that of commercial boehmite.

As outlined below, several authors have described the direct conversion of kaolin into $\gamma-\mathrm{Al}_{2} \mathrm{O}_{3}$ without the formation of boehmite. This is achieved by reacting kaolin with concentrated base solution.

Okada, et al. [9] described the synthesis of $\gamma-\mathrm{Al}_{2} \mathrm{O}_{3}$ from calcined kaolin via the selective extraction of the amorphous $\mathrm{SiO}_{2}$ phase by concentrated $\mathrm{KOH}$ solution. The solid residue remaining after the extraction was identified as having a spinel structure, containing $\gamma-\mathrm{Al}_{2} \mathrm{O}_{3}$ and a minor content of crystalline 
$\mathrm{SiO}_{2}$. Saito, et al. [10] studied the effect of kaolin calcination temperature on the pore structure of $\gamma-\mathrm{Al}_{2} \mathrm{O}_{3}$ produced via extraction by $\mathrm{KOH}$ solution. At calcination temperatures in the $950-1050^{\circ} \mathrm{C}$ range, these authors obtained a specific surface area of $250 \mathrm{~m}^{2} / \mathrm{g}$.

Extraction by acidic solution represents another route for the synthesis of $\gamma-\mathrm{Al}_{2} \mathrm{O}_{3}$ from kaolin. Contrary to the basic solution extraction route, the acidic solution extracts the alumina phase from the kaolin crystal structure. This implies that the acid extraction route necessarily involves additional steps to recover the alumina from the extract, and to convert the recovered solid material to $\gamma-\mathrm{Al}_{2} \mathrm{O}_{3}$ by calcination.

Belver, et al. [11] described the reaction between a Spanish kaolin calcined between $600-900^{\circ} \mathrm{C}$ and concentrated $\mathrm{HCl}$ solution. This reaction removes most of the octahedral $\mathrm{Al}^{3+}$ from the kaolin crystal structure, leaving behind a network structure consisting of amorphous silica phase.

Yang, et al. [12] also described a synthesis route of $\gamma-\mathrm{Al}_{2} \mathrm{O}_{3}$ from kaolin by acid extraction. The suspension extract produced by contacting kaolin and concentrated $\mathrm{HCl}$ solution was filtered and precipitated by adding ammonia. The obtained precipitate contained boehmite and aluminum hydroxide, which started to form $\gamma-\mathrm{Al}_{2} \mathrm{O}_{3}$ at $537^{\circ} \mathrm{C}$ during calcination.

\section{$3 \quad$ Methodology}

\subsection{Materials and Equipment}

The kaolin utilized in this study was obtained from the Belitung island via the Center for Ceramic Research (Balai Besar Keramik) of the Ministry of Industry of the Republic of Indonesia in the city of Bandung. Oxide composition of this material was characterized by the wet chemical method at the Mining Engineering Program laboratory facility in Bandung Institute of Technology, and the results are presented in Table 2. As a comparison, typical composition of Georgia (USA) fiberglass-grade kaolin [13] is included in the table. The oxide compositions of the two minerals are generally similar, except for the higher $\mathrm{CaO}$ and $\mathrm{Na}_{2} \mathrm{O}$ contents of the Belitung kaolin.

Concentrated aqueous solution of $\mathrm{KOH}$ was selected as the solvent to extract the silica phase, in accordance to Okada's method [9] which served as the baseline synthesis method. Selection of $\mathrm{KOH}$ was also based on unpublished preliminary trials by one of the co-authors, which in general produced less than 
satisfactory specific surface areas. An analytical grade KOH (Merck Emsure $^{\circledR}$ ) was used to prepare the $\mathrm{KOH}$ solution.

Table 2 Oxide composition of the Belitung kaolin sample.

\begin{tabular}{ccc}
\hline Component & Belitung & Georgia, USA \\
\hline $\mathrm{SiO}_{2}$ & 46.77 & $<45.0 \pm 0.6$ \\
$\mathrm{Al}_{2} \mathrm{O}_{3}$ & 38.17 & $>38.5 \pm 0.5$ \\
$\mathrm{Fe}_{2} \mathrm{O}_{3}$ & 0.37 & $<0.50 \pm 0.05$ \\
$\mathrm{TiO}_{2}$ & 0.22 & $<1.4 \pm 0.03$ \\
$\mathrm{CaO}$ & 0.64 & $<0.2 \pm 0.05$ \\
$\mathrm{MgO}$ & 0.14 & $<0.3 \pm 0.1$ \\
$\mathrm{Na}_{2} \mathrm{O}$ & 0.12 & $<0.03 \pm 0.01$ \\
$\mathrm{~K}_{2} \mathrm{O}$ & 0.10 & $<0.20 \pm 0.1$ \\
Loss on ignition & 13.47 & $>14.0 \pm 0.5$ \\
\hline
\end{tabular}

\subsection{Synthesis Method}

The base extraction method described by Okada, et al. [9] was selected as the basis of the processing route of the Belitung kaolin. This synthesis route was selected due to its simplicity and lower consumption of reagents compared to the acid extraction route. The base extraction method based on the work of Okada, et al. [9] is outlined in Table 3.

Table 3 Base extraction route used as the baseline synthesis procedure.

\begin{tabular}{cl}
\hline Step no. & \multicolumn{1}{c}{ Description } \\
\hline 1 & $\begin{array}{l}\text { Raw kaolin is comminuted in a ball mill for } 15 \text { minutes to remove agglomerates } \\
\text { Kaolin is calcined in an electric furnace at } 950^{\circ} \mathrm{C} \text { for } 24 \text { hours in ambient air } \\
\text { atmosphere }\end{array}$ \\
3 & $\begin{array}{l}\text { One gram of calcined kaolin is extracted by } 250 \mathrm{~mL} 4.0 \mathrm{M} \mathrm{KOH} \text { solution at } 90^{\circ} \mathrm{C} \text { for } \\
1 \text { hour in a beaker glass on an electric plate heater equipped with a magnetic stirrer }\end{array}$ \\
4 & $\begin{array}{l}\text { The remaining solid residue is separated by centrifuging and decantation, followed } \\
\text { by washing by } 0.5 \mathrm{M} \mathrm{KOH} \text { solution, and double-washing with demineralized water } \\
5\end{array}$ \\
$\begin{array}{l}\text { The washed residue is then dried in an electric oven at } 110^{\circ} \mathrm{C} \text { overnight and stored } \\
\text { for characterization }\end{array}$
\end{tabular}

Since the objective of this preliminary research stage is to demonstrate the technical feasibility of Belitung kaolin utilization as a $\gamma-\mathrm{Al}_{2} \mathrm{O}_{3}$ precursor, modifications to the baseline method outlined in Table 3 were undertaken to obtain a specific surface area of at least $200 \mathrm{~m}^{2} / \mathrm{g}$, which refers to the intermediate value of that of hydrodesulfurization and hydrodenitrogenation catalysts for distillates [14]. These modifications were explored by the onefactor-at-a-time method as described by Montgomery in his classic text on statistical experimental design [15], in which the calcination temperature and time were varied alternately. While not as efficient as a statistically designed experiment, the one-factor-at-a-time was selected due to the lack of published 
data on the range of values within which calcination temperature and time should be varied for Belitung kaolin.

\subsection{Sample Characterization}

Solid-phase physical properties characterization included morphological evaluation by scanning electron microscopy (SEM), phase identification by Xray diffraction (XRD) and specific surface area and pore volume measurement by inert gas adsorption. These characterizations were aimed at evaluating the changes occurring during processing and to measure the key engineering properties of the product.

The XRD characterization was undertaken for the kaolin raw material, metakaolin intermediate, and $\gamma-\mathrm{Al}_{2} \mathrm{O}_{3}$ product. The XRD instrument unit was a Phillips PW1710 operated by the Mining Engineering Program in Bandung Institute of Technology. The $2 \theta$ angle range was set between 5 to $75^{\circ}$, with a step size of $0.02^{\circ}$ and dwell time of 0.50 second. The SEM analysis was undertaken at the Environmental Geology Research Center facility of the Ministry of Energy and Mineral Resources in Bandung.

The inert gas adsorption measurement was undertaken on a Quantachrome Nova 1000 high-speed gas sorption analyzer at the Chemical Engineering Program in Bandung Institute of Technology. High-purity nitrogen (BOC Gases/PT. Aneka Gas, Bandung) was used as the sorbent inert gas. Treatment of the nitrogen adsorption-desorption data resulted in specific surface area determination by the BET (Brunauer-Emmett-Teller) method, mesopore size distribution by the BJH (Barnett-Joyner-Halenda) method, and pore volume.

\section{$4 \quad$ Results and Discussion}

\subsection{Product Properties from the Exploratory Experiment}

To evaluate the applicability of the base extraction route for Belitung kaolin as measured against the targeted specific surface area, modifications on the synthesis variables in the original procedure by Okada, et al. [9] were undertaken. The calcination temperature was varied at 950 and $1000^{\circ} \mathrm{C}$, the calcination time was varied at 1,12 , and 24 hours, and the extraction time was varied at 1 and 12 hours. These relatively large ranges of variation were selected to create a substantial change in the specific surface area of the final product.

Table 4 presents the combinations of calcination temperature, calcination time, and extraction time selected in this exploratory study. Three sets of experiments were undertaken. Characteristics of the synthesized products are also listed in 
the table, which include specific surface area, median size of the mesopores, and pore volume.

Table 4 Summary of the exploratory experiment results.

\begin{tabular}{|c|c|c|c|c|c|c|c|}
\hline $\begin{array}{c}\text { Experi } \\
\text {-ment } \\
\text { no. }\end{array}$ & $\begin{array}{l}\text { Batc } \\
\text { h no. }\end{array}$ & $\begin{array}{c}\text { Calcination } \\
\quad \mathbf{T},{ }^{\circ} \mathrm{C}\end{array}$ & $\begin{array}{c}\text { Calcination } \\
\text { time, hrs }\end{array}$ & $\begin{array}{c}\text { Extraction } \\
\text { time, hrs }\end{array}$ & $\begin{array}{c}\text { Specific } \\
\text { surface } \\
\text { area, } \\
\mathrm{m}^{2} / \mathrm{g}\end{array}$ & $\begin{array}{c}\text { Median } \\
\text { mesopore } \\
\text { size, } \AA\end{array}$ & $\begin{array}{c}\text { Pore } \\
\text { volume, } \\
\mathrm{cm}^{3} / \mathrm{g}\end{array}$ \\
\hline \multirow{3}{*}{ I } & 1 & 950 & 22 & 1 & 21.2 & 14.4 & 0.012 \\
\hline & 2 & 950 & 24 & 1 & 50.0 & 14.6 & 0.030 \\
\hline & 3 & 950 & 25 & 1 & 54.8 & 14.5 & 0.033 \\
\hline \multirow{3}{*}{ II } & 4 & 950 & 6 & 12 & 160.0 & 14.6 & 0.10 \\
\hline & 5 & 950 & 24 & 12 & 182.9 & 14.4 & 0.12 \\
\hline & 6 & 950 & 42 & 12 & 220.0 & 14.4 & 0.14 \\
\hline \multirow{3}{*}{ III } & 7 & 750 & 24 & 12 & 91.6 & 14.0 & 0.055 \\
\hline & 8 & 850 & 24 & 12 & 112.3 & 14.0 & 0.068 \\
\hline & 9 & 1000 & 24 & 12 & 233.5 & 14.1 & 0.14 \\
\hline
\end{tabular}

The first experiment listed in Table 4 was a first attempt at proving the direct applicability of the method described by Okada, et al. [9] to the Belitung kaolin sample. Thus, the calcination time was varied in a relatively narrow range, i.e. between $22-25$ hours. Calcination temperature was kept at $950^{\circ} \mathrm{C}$ due to risk of mullite $\left(3 \mathrm{Al}_{2} \mathrm{O}_{3} \cdot 2 \mathrm{SiO}_{2}\right)$ formation in the vicinity of $980-1000^{\circ} \mathrm{C}$ as described by several authors (see, for example, classical papers by Brindley and Nakahira [16], Chakraborty and Ghosh [17], and MacKenzie, et al. [18]). Mullite is a well-crystallized refractory aluminosilicate phase, considered to have a low reactivity towards chemical attack. The specific surface area data obtained from the first experiment clearly indicate that the base extraction method described by Okada, et al. [9] cannot be applied to Belitung kaolin without any modification, since it only produced a specific surface area of $22-52 \mathrm{~m}^{2} / \mathrm{g}$.

In the second experiment, the effect of calcination time was evaluated by varying this variable between 6 to 42 hours while keeping the temperature constant at $950^{\circ} \mathrm{C}$ and extraction time of 12 hours. Longer calcination time increased the specific surface area and pore volume, while the pore size did not appear to be substantially impacted. With a calcination time of 42 hours, a specific surface area of approximately $220 \mathrm{~m}^{2} / \mathrm{g}$ was obtained, thus exceeding the minimum target of $200 \mathrm{~m}^{2} / \mathrm{g}$. Compare with the first experiment suggests that increasing the calcination time from 1 to 12 hours resulted in a substantial increase of surface area. However, the same comparison also suggests that an increase of calcination time alone is not likely to be sufficient to produce the desired minimum specific surface area (compare Batch no. 2 and 5 in Table 4). 
The third experiment included in Table 4 was undertaken to measure the effect of calcination temperature, which was varied at 750,850 , and $1000^{\circ} \mathrm{C}$. As the numbers in Table 4 clearly suggest, an increase in calcination temperature improves the specific surface area and pore volume. Similar to the first and second experiments, the median pore size did not appear to be substantially impacted by any changes in calcination process parameters. Calcination temperatures of 750 and $850^{\circ} \mathrm{C}$ were apparently not high enough to produce the desired surface area. When the kaolin calcination was undertaken at $1000{ }^{\circ} \mathrm{C}$, the specific surface area of the final product was approximately $233 \mathrm{~m}^{2} / \mathrm{g}$. This value is substantially higher than the targeted $200 \mathrm{~m}^{2} / \mathrm{g}$, and was the highest surface area obtained in this preliminary study.

\subsection{Phase and Morphological Development during Conversion of Kaolin to $\gamma-\mathrm{Al}_{2} \mathrm{O}_{3}$}

Figure 3 presents the $\mathrm{X}$-Ray diffractograms of the three materials representing the phase development occurring during the conversion of kaolin into $\gamma-\mathrm{Al}_{2} \mathrm{O}_{3}$. These are the raw Belitung kaolin, the metakaolin or calcined kaolin, and the $\gamma$ $\mathrm{Al}_{2} \mathrm{O}_{3}$ product. Phase designations of the diffraction peaks are included in Figure 3. These diffractograms were measured using the same instrument, at the identical operating parameters setting.

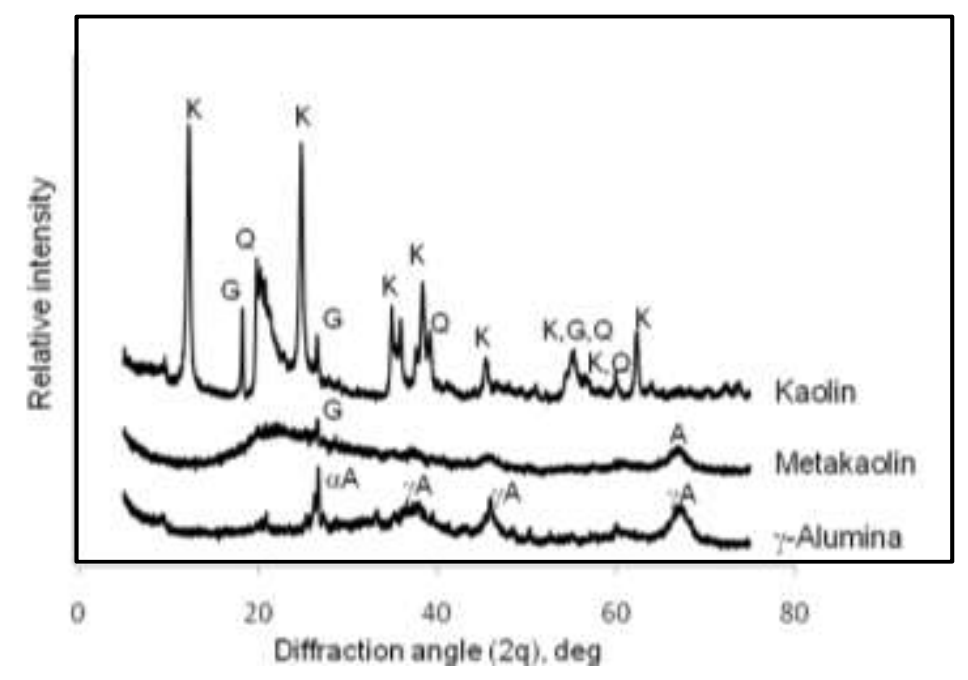

Figure 3 X-ray diffractograms of Belitung kaolin, metakaolin (calcined at $950^{\circ} \mathrm{C}$ for 24 hours), and the final $\gamma-\mathrm{Al}_{2} \mathrm{O}_{3}$ product (Note: $\mathrm{A}=$ alumina, $\alpha \mathrm{A}=\alpha$ $\mathrm{Al}_{2} \mathrm{O}_{3}, \gamma \mathrm{A}=\gamma-\mathrm{Al}_{2} \mathrm{O}_{3}, \mathrm{G}=$ gibbsite, $\mathrm{K}=$ kaolinite, $\mathrm{Q}=$ quartz). 
The particular metakaolin in Figure 3 was produced by calcining the raw kaolin at $950^{\circ} \mathrm{C}$ for 24 hours as described by Okada, et al. [9]. The near-amorphous nature of this intermediate material is implied by the disappearance of kaolinite peaks. The sharp quartz peak near $2 \theta=20^{\circ}$ in kaolin was broadened, suggesting a substantial shift in the long-range order of the crystalline silica phase towards a predominantly short-range order, albeit with the preservation of the $\mathrm{SiO}_{4}{ }^{-}$ tetrahedra as the smallest repeating unit containing $\mathrm{Si}$ atoms. As described by Lee [19], the dehydroxylation of kaolin during calcination destroys the hexagonal $\mathrm{Al}(\mathrm{O}, \mathrm{OH})_{6}$ octahedral sheet, but does not have much effect on the $\mathrm{SiO}_{4}$ tetrahedral sheet. A new phase also appeared in the metakaolin, indicated by the rather faint $\mathrm{Al}_{2} \mathrm{O}_{3}$ peak at $2 \theta=66^{\circ}$.

The phase identity of the synthesized product is presented as the bottom graph in Figure 3. The list of diffraction peaks of the product in Figure 3 is presented in Table 5. With the exception of the peak at $26.7^{\circ}$, the peaks observed for the final product are quite consistent with those of the pure $\gamma-\mathrm{Al}_{2} \mathrm{O}_{3}$ phase described by Meephoka, et al. [20], which exhibits diffraction peaks at $2 \theta$ angles of 32, $37,39,45,61$, and $66^{\circ}$. Yang, et al. [12] also observed a rather weak peak in the vicinity of $2 \theta=27^{\circ}$ in their boehmite phase. These authors observed that this peak intensifies after calcination at $1000^{\circ} \mathrm{C}$, and assigned this peak to the $\alpha$ $\mathrm{Al}_{2} \mathrm{O}_{3}$ phase.

Table 5 X-ray diffraction peak angles and relative intensities of $\gamma-\mathrm{Al}_{2} \mathrm{O}_{3}$ product obtained by calcination at $950^{\circ} \mathrm{C}$ for 24 hours.

\begin{tabular}{cc}
\hline $\begin{array}{c}\text { Diffraction angle (20) } \\
(\mathbf{(})\end{array}$ & $\begin{array}{c}\text { Relative intensity } \\
(\boldsymbol{\%})\end{array}$ \\
\hline 26.72 & 100.0 \\
33.2 & 55.4 \\
36.6 & 65.1 \\
37.8 & 64.5 \\
45.9 & 65.6 \\
60.0 & 42.6 \\
66.6 & 60.8 \\
\hline
\end{tabular}

The morphological changes occurring during the conversion of kaolin to metakaolin, and after the subsequent leaching by $\mathrm{KOH}$ solution are described by scanning electron micrographs in Figure 4(a) through 4(c). Comparison of the morphology of the Belitung kaolin and metakaolin obtained after calcination at $1000^{\circ} \mathrm{C}$ for 24 hours indicates the breakdown of the layered kaolinite structure. 
Qualitatively, the microstructure of the metakaolin was dominated by acicular particles with relatively rounded edges. Figure $4(\mathrm{c})$ is the electron micrograph of the product obtained by leaching the metakaolin in Figure 4(b) for 12 hours. The morphology of the solid phase remaining after leaching by $\mathrm{KOH}$ solution exhibited a cubic crystal habit, consistent with the crystal structure of the $\gamma$ $\mathrm{Al}_{2} \mathrm{O}_{3}[21]$.

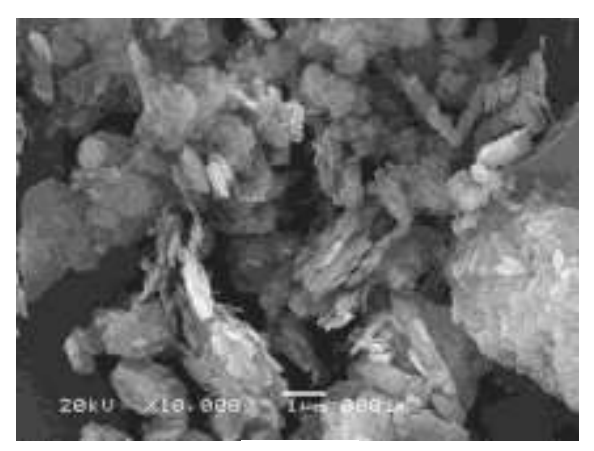

(a)

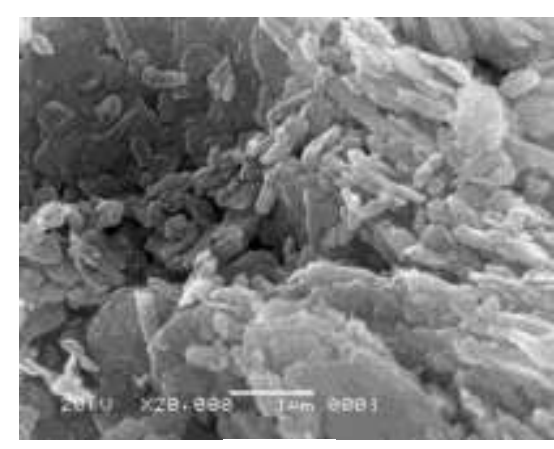

(b)

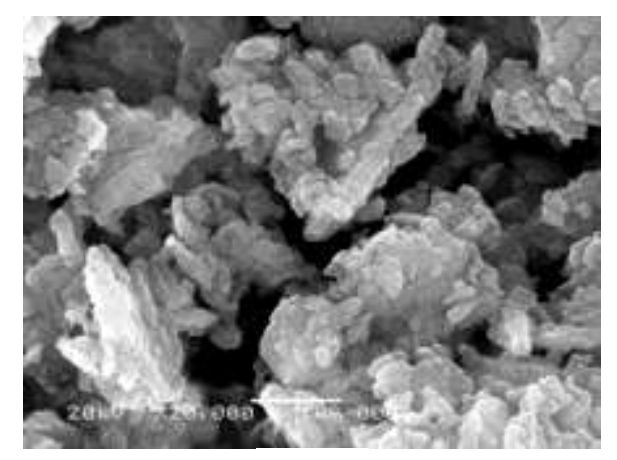

(c)

Figure 4 Scanning electron micrographs of: (a) raw Belitung kaolin (b) metakaolin obtained after calcination of kaolin at $1000^{\circ} \mathrm{C}$ and 24 hours (c) $\gamma$ $\mathrm{Al}_{2} \mathrm{O}_{3}$ obtained after leaching with 4.0 M KOH for 12 hours.

\section{$5 \quad$ Conclusions and Recommendations}

The technical feasibility of applying the base extraction process to produce $\gamma$ $\mathrm{Al}_{2} \mathrm{O}_{3}$ suitable for hydrotreating catalyst support material from Belitung kaolin has been verified. Three key synthesis variables (kaolin extraction time, and metakaolin calcination time and temperature) have been identified in this work. Compared to the published synthesis method, this study suggests that a very large increase (approximately tenfold) in kaolin extraction time and a moderate 
increase (approximately twofold) in metakaolin calcination time are necessary to obtain the desired minimum specific surface area of $200 \mathrm{~m}^{2} / \mathrm{g}$. Substantial increase in the specific surface area may be obtained by a relatively small increase in metakaolin calcination temperature from 950 to $1000^{\circ} \mathrm{C}$.

Recommended items for future work include performing a statistically designed experiment to quantify the effects of the above variables, validating the improved base-extraction synthesis route, and evaluating the extrusion / shaping behavior of the bulk $\gamma-\mathrm{Al}_{2} \mathrm{O}_{3}$. Finally, the need for a study on the formulation and performance evaluation of the hydrotreating catalyst using the obtained $\gamma$ $\mathrm{Al}_{2} \mathrm{O}_{3}$ as the support material is imminent.

\section{Acknowledgments}

The authors wish to extend their most sincere gratitude to the Bandung Intitute of Technology Alumni Association for the financial support of this research via the ITB Alumni Association Research Grant 2010 program, and to the Faculty of Industrial Technology at Bandung Institute of Technology for administering the disbursement of the research fund.

\section{References}

[1] Silvy, R.P., Future Trends in the Refining Catalyst Market, Applied Catalysis A: General, 261, 247-252, 2004.

[2] Anonymous, Refinery Catalysts: Fuels Drive Growth, Chemical Week, 25 April 2007, http://goliath.ecnext.com/coms2/gi_0199-6546135/Refinerycatalysts-fuels-drive-growth.html, (18 May 2010).

[3] Anonymous, Mining Potential (in Indonesian), Bangka Belitung Island Province Mining \& Energy Service, http://distambenpropbabel.net (19 May 2010).

[4] Anonymous, West Kalimantan Province: Regional Quality of Life Balance Resources - NKLD 2000 (in Indonesian), Ministry of the Environment of the Republic of Indonesia, http://www.menlh.go.id/i/art/ pdf_1065227328.pdf (19 May 2010).

[5] Anonymous, South Kalimantan, World Friend Indonesia, http://worldfriend.web.id/ indonesia/kalimantan-selatan- (19 May 2010).

[6] Chorkendorff, I. \& Niemantsverdriet, J.W., Concepts of Modern Catalysis and Kinetics, Wiley-VGH Verlag, Weinheim, Germany, pp.189-193, 355-356, 2003.

[7] Richardson, J.T., Principles of Catalyst Development, Plenum Press, New York, p. 104, 1989. 
[8] Huang, W.L., Stability and Kinetics of Kaolinite to Boehmite Conversion Under Hydrothermal Conditions, Chemical Geology, 105, 197-214, 1993.

[9] Okada, K., Kawashima, H., Saito, Y., Hayashi, S. \& Yasumori, A., New Preparation Method for Mesoporous $\gamma$-Alumina by Selective Leaching of Calcined Kaolin Minerals, Journal of Materials Chemistry, 5(8), 12411244, 1995.

[10] Saito, Y., Hayashi, S., Yasumori, A. \& Okada, K., Effects of Calcining Conditions of Kaolinite on Pore Structures of Mesoporous Materials Prepared by the Selective Leaching of Calcined Kaolinite, Journal of Porous Materials, 3, 233-239, 1996.

[11] Belver, C., Munoz, M.A.B. \& Vicente, M.A., Chemical Activation of a Kaolinite under Acid and Alkaline Conditions, Chemistry of Materials, 14, 2033-2043, 2002.

[12] Yang, H., Liu, M. \& Jing, O., Novel Synthesis and Characterization of Nanosized $\gamma-\mathrm{Al}_{2} \mathrm{O}_{3}$ from Kaolin, Applied Clay Science, 47, 438-443, 2010.

[13] Kogel, J.E., Pickering, S.M., Sheloboline, E., Chowns, T., Yuan, J., \& Avant, D.M., The Georgia Kaolins: Geology and Utilization, Society for Mining, Metallurgy, and Exploration, Inc., Littleton, Colorado, USA, pp. 31-33, 2002.

[14] Eijsbouts, S., Hydrotreating Catalysts, Synthesis of Solid Catalysts, de Jong, K.P. (ed.), Wiley-VCH Verlag, Weinheim, Germany, pp. 301-303, 2009.

[15] Montgomery, D.C., Design and Analysis of Experiments, $5^{\text {th }}$ ed., J. Wiley \& Sons, New York, pp.3-5, 2001.

[16] Brindley, G.W. \& Nakahira, M., The Kaolinite-Mullite Reaction Series I: A Survey of Outstanding Problems, Journal of the American Ceramic Society, 42(7), 311-314, 1959.

[17] Chakraborty, A.K. \& Ghosh, D.K., Reexamination of the Kaolinite-toMullite Reaction Series, Journal of the American Ceramic Society, 61(34), 170-173, 1978.

[18] MacKenzie, K.J.D., Meinhold, R.H., Brown, I.W.M. \& White, G.V., The Formation of Mullite from Kaolinite under Various Reaction Atmospheres, Journal of the European Ceramic Society, 16, 115-119, 1996. 
[19] Lee, S., Kim, Y.J. \& Moon, H., Phase Transformation from Kaolinite to Mullite Investigated by an Energy-Filtering Transmission Electron Microscope, Journal of the American Ceramic Society, 82(10), 28412848, 1999.

[20] Meephoka, C., Chaisuk, C., Samparnpiboon, P., \& Praserthdam, P., Effect of Phase Composition Between Nano $\gamma$ - and $\chi-\mathrm{Al}_{2} \mathrm{O}_{3}$ on $\mathrm{Pt}_{\mathrm{Al}} \mathrm{Al}_{2} \mathrm{O}_{3}$ Catalyst in CO Oxidation, Catalysis Communications, 9(4), 546-550, 2008.

[21] Kingery, W.D., Bowen, H.K. \& Uhlmann, D.R., Introduction to Ceramics, 2nd ed., John Wiley \& Sons, Singapore, p. 81, 1991. 